Studien zur Geschichte und Theorie der dramatischen Künste

Herausgegeben von Hans-Peter Bayerdörfer, Dieter Borchmeyer und Andreas Höfele

Band 34 

Franz Anton Cramer

\section{Der unmögliche Körper}

Etienne Decroux

und die Suche nach dem theatralen Leib

Max Niemeyer Verlag

Tübingen 2001

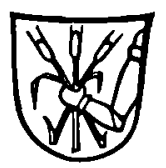


Die Deutsche Bibliothek - CIP-Einheitsaufnahme

\section{Cramer, Franz Anton:}

Der unmögliche Körper: Etienne Decroux und die Suche nach dem theatralen Leib / Franz Anton Cramer. - Tübingen: Niemeyer, 2001

(Theatron; Bd. 34)

\section{ISBN 3-484-66034-1 ISSN 0934-6252}

(C) Max Niemeyer Verlag GmbH, Tübingen 2001

Das Werk einschließlich aller seiner Teile ist urheberrechtlich geschützt. Jede Verwertung außerhalb der engen Grenzen des Urheberrechtsgesetzes ist ohne Zustimmung des Verlages unzulässig und strafbar. Das gilt insbesondere für Vervielfăltigungen, Übersetzungen, Mikroverfilmungen und die Einspeicherung und Verarbeitung in elektronischen Systemen.

Printed in Germany.

Gedruckt auf alterungsbeständigem Papier.

Druck: AZ Druck und Datentechnik GmbH, Kempten

Einband: Buchbinderei Siegfried Geiger, Ammerbuch 